\title{
Development of a New Inflatable Controlled Anchor System and Experimental Study of pull-out Capacity
}

\author{
Xuexiang Yang $\mathbb{D}$, ${ }^{1}$ Shanpo Jia $\left(\mathbb{D},{ }^{2,3}\right.$ Caoxuan Wen $\left(\mathbb{D},{ }^{1}\right.$ and Yuanjie Liu ${ }^{1}{ }^{1}$ \\ ${ }^{1}$ School of Urban Construction, Yangtze University, Jingzhou 434023, China \\ ${ }^{2}$ Institute of Unconventional Oil \& Gas, Northeast Petroleum University, Daqing 163318, China \\ ${ }^{3}$ Research Center of Geomechanics and Geotechnical Engineering, Yangtze University, Jingzhou 434023, China \\ Correspondence should be addressed to Shanpo Jia; jiashanporsm@163.com and Caoxuan Wen; 15827943468@163.com
}

Received 12 December 2018; Accepted 18 March 2019; Published 30 April 2019

Academic Editor: Cumaraswamy Vipulanandan

Copyright (c) 2019 Xuexiang Yang et al. This is an open access article distributed under the Creative Commons Attribution License, which permits unrestricted use, distribution, and reproduction in any medium, provided the original work is properly cited.

Considering the deficiency of traditional anchors, we propose a new type of inflatable controlled anchor system in this paper. The working mechanism and its structural composition of newly designed inflatable controlled device are discussed in detail. To investigate the performance and pull-out capacity of this new anchor system, a series of field tests were carried out under different inflation pressure conditions. By comparing these test results with those of traditional grouting anchors, a full-process constitutive model of anchor-soil interface is proposed to depict the pull-out characteristics of the inflatable controlled anchor. The results show that the ultimate bearing capacity of the inflatable controlled anchor is greater than that of the traditional grouting anchor when the inflation pressure is greater than $0.2 \mathrm{MPa}$ and the ultimate bearing capacity of this new anchor improves obviously with the increase of inflation pressure. When the inflation pressure reaches $0.4 \mathrm{MPa}$, the ultimate bearing capacity of the inflatable controlled anchor is 2.08 times that of the traditional grouting anchor. Through comparison with the experimental curves, the results of model calculation indicate that the proposed anchor-soil interface constitutive equation can describe the pull-out characteristics of the inflatable controlled anchor. The designed controlled anchor has the advantages of no grouting, recyclability, rapid formation of anchoring force, and adjustable anchoring force.

\section{Introduction}

The geotechnical anchoring technology, which is used to bury the tensile rod into soil, can improve its own strength and stability of the stratum, and prevent the disaster damage of the soil such as collapse, landslide and land subsidence during the construction process $[1,2]$. In recent 30 years, geotechnical anchoring technology has become the key research object in modern geotechnical engineering and has also developed rapidly in engineering applications.

Geotechnical anchoring technology has been fully applied in deep foundation engineering, antifloating structure engineering, high-steep slope engineering, dam reinforcement engineering, tunnel engineering, and highway engineering because of its advantages of safety, economy, and effectiveness. In recent years, the application scope of the geotechnical anchoring technique increases gradually.
For meeting requirements of different geological conditions, working environment, and bearing capacity, a variety of new type anchors were developed successively, such as the splitset anchor, the water swelling anchor, the flexible pressurized grouting anchor, the inflatable anchor, and the inflatable anchor with the end baffle [3]. The split-set anchor, which is forcibly squeezed by external force into the vertical slit steel pipe with a larger diameter than that of drilling hole, achieves the anchoring effect through the fiction produced by mechanical external force between anchor and the hole wall $[4,5]$. The main disadvantage of the thin-walled split anchor is that the anchoring force is not easy to control and is greatly influenced by the difference between the pipe diameter and the anchor hole diameter. When the difference of two diameters is small, it is difficult to install the split-set anchor, while the anchoring force is very small when the diameter difference is large. Furthermore, the split-set 
anchor is difficult to recycle and reuse after use. The water swelling anchor, which is fabricated into double concave tubular rod, is developed by injecting high-pressure water to expand the thin seamless steel pipe and squeeze the anchor hole wall [6]. The main disadvantages of the water swelling anchor include that the recovered anchor has almost no reuse value, the use of double-layer seamless steel pipe has a high requirement on the high costing material and manufacturing technology, and its large internal pressure is not suitable for soft soil. The flexible pressurized grouting anchor with the similar principle of the water swelling anchor can only be used in rock layers with small deformation or soft rock conditions as its maximum deformation should not exceed 30\% [7], so it is not suitable for highly deformed soil layers. The inflatable anchor, first proposed by Professor Tim Newson in 2000, forms an expansion head of rubber membrane and squeezes the soil hole wall by inflation pressure and then offers anchoring force [8-10].

To overcome the disadvantages of aforementioned anchors, an inflatable controlled anchor system, the methodology, and the testing device are described in this paper. By conducting the pull-out test of the proposed anchor under different inflation pressures, the performance and uplift capacity are discussed, and then a full-process constitutive model is developed to describe the mechanical properties of the anchor-soil interface.

\section{Design and Manufacture of Inflatable Controlled Anchor}

2.1. Design Principle. The construction of the current inflatable anchor includes a rubber membrane fixed on the outside the hollow steel tube, which is shown in Figure 1(a). After the inflatable anchor is placed in the drilled hole and filled with a certain pressure of gas through the anchor rod, the rubber membrane expands and forms a waist drumshaped enlarged head, and the soil around the rubber membrane is squeezed to generate an anchoring effect $[11,12]$. The expansion process of inflatable anchor is shown in Figure 1(b). Although some advantages of inflatable anchor, including fully recoverable and green, have been recognized by many experts, the limitations of inflatable anchor include the easy blasting failure of rubber membrane under high inflation pressure, low pull-out bearing capacity, and excessive ultimate displacement, which make this type of anchor unable to meet the practical demand in engineering.

In consideration of the defects of the current inflatable anchor, the following improvements have been made in this study: (1) Two baffles are provided at the front and rear ends of anchor to restrict the inflation deformation of rubber membrane in the axial direction. (2) The rubber membrane is separated from the steel tube and has a self-inflatable pipeline with a middle hole. (3) The steel tube is no longer used as an inflation channel but as the tensile rod to transmit the anchoring tension.

The inflatable controlled anchor is provided with an expansion device in the anchored zone, and the anchored effect is achieved by frictional resistance between the outer surface of expansion device and soil wall of drilled hole. The proposed inflatable controlled anchor system is shown in Figure 2. For combination with its actual engineering demand, the structure of inflatable controlled anchor system has the following characteristics: (1) The squeezing device has sufficient rigidity and strength, can have radial stretching performance under external force, and can automatically retract when the external force disappears. (2) Squeezing force is controlled by inflation pressure in expansion device that can be adjusted at any time according to the practical engineering demand. (3) Considering that the force transmission device needs to be recovered in a narrow space, it is made into the segmented connection structure and fixedly connected with the squeezing device.

In the anchored zone, the inflatable controlled anchor is provided with a squeezing device, in which a special expansion device can control and set the squeezing force dynamically. When the expansion device is controlled to expand radially by inflation pressure, the squeezing device is pushed and pressed against the soil wall of drilled hole. After the anchor system is pulled out, the friction between the soil wall and squeezing device is generated, and thus the anchored force system is formed by the force transmission device. When the anchoring target is achieved, the expansion device shrinks by decreasing inflation pressure in the control device, and the squeezing device is detached from the anchor hole wall. Thus, the anchor system in the hole can be recovered, which has great environmental protection value and economic benefit for temporary anchorage of foundation pits and other temporary projects.

2.2. Manufacture Process. To facilitate the construction and recovery of the anchor, the inflatable controlled anchor system is made of four separate parts: squeezing device, expansion device, force transmission device, and control device, so as to realize a distributed manufacture and an easy-to-assemble construction process.

2.2.1. Squeezing Device. The squeezing device is located in the outermost layer of the inflatable controlled anchor, and its main function is to provide an anchoring force according to the generated resistance contacted with the soil. It is the key work to choose a suitable squeezing device with certain rigidity and strength as well as good springback function. The steel has high stiffness and strength, which is the first choice material for squeezing device as it can withstand a large tensile force in anchoring section, so as to provide the high load-bearing capacity.

To ensure the expansion deformation capacity and springback performance of steel tube, the circular steel tube is equally divided into longitudinal strips as squeezing steel. When the steel tube is not subjected to the inflation pressure, the steel strips can be folded into a circular tube, which is shown in Figure 3. When the inflation pressure in the rubber membrane is applied, each squeezing steel strip can expand evenly with the expansion of the rubber membrane. The material of squeezing device is made of stainless steel tube, 


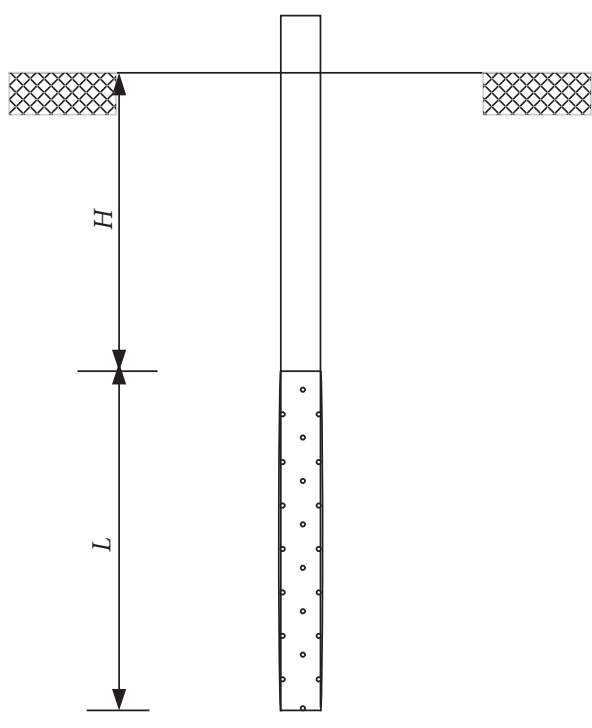

(a)

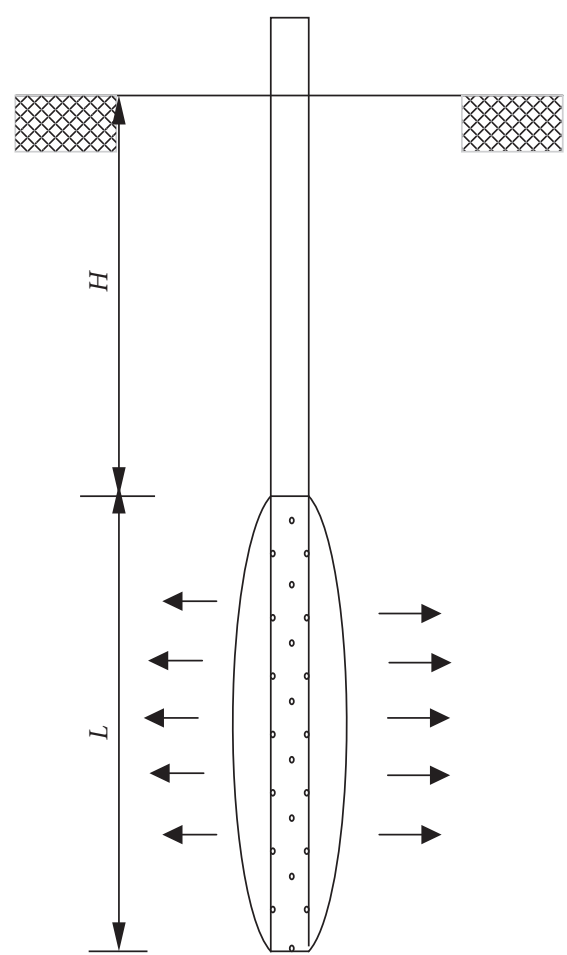

(b)

Figure 1: Current inflatable anchor. (a) The anchor placed in the drilled hole. (b) The expansion of anchor.

which expands or contracts with the volume change of rubber membrane. According to many laboratory tests, the comparison of different squeezing steel strips is shown in Table 1.

Considering the expansion property of steel strips, structure form, and manufacture processing, the foursection cutting structure, that is, the steel tube divided into four equal parts longitudinally, is applied as the squeezing device in the proposed anchor system (as shown in Figure 4). To limit the expansion deformation of rubber membrane at two ends under inflation pressure, the upper and lower ends of each steel strip are welded to be a fanshaped bracket. The upper bracket of steel strip is also fanshaped and welded by multiple sleeves, so as to facilitate the fixed connection of the steel strips and the tension bars. Four squeezing steel strips form a circle just after they are closed, which is shown in Figure 5.

2.2.2. Expansion Device. The expansion device is designed in the innermost layer of the anchor system (as shown in Figure 6), which is as an expansion part and only provides the expansion force for the squeezing device. The main part used in the expansion device is a rubber membrane, mainly used to seal and keep inflation pressure and expand the steel strips. The expansion device not only has higher bearing strength and sealing performance but also have large deformation characteristics. Generally, the performance requirements of rubber membrane are as follows: (1) The rubber membrane should have high strength and not burst when carrying high internal injection pressure. (2) It should have good expansion performance that can be expanded at very small inflation pressure, and the expansion rate can reach more than $200 \%$. (3) It has good air tightness and no air leakage, in which the air pressure is stable under high inflation pressure.

To ensure the sealing, pressure resistance, large deformation, and other characteristics of the rubber membrane, the expansion device adopts butyl rubber as the material for expansion membrane. The rubber membrane used in this study is all made by the rubber factory.

2.2.3. Force Transmission Device. The function of transmission device is to transfer load, and it should have higher tensile strength. As an excellent tensile material, the steel bar is the preferred material for the force transmission device. According to the ultimate bearing capacity tests of tensile force, the HRB335 (Hot-rolled Ribbed Bar) with a diameter of $8 \mathrm{~mm}$ is selected as the tension bar for force transmission device, which is shown in Figure 7. To facilitate the recovery of anchor in narrow space, the tension bar can be constructed by piecewise connection for deep hole.

2.2.4. Control Device. The main function of control device is inflation and pressure relief of rubber membrane. The control pipeline is mainly composed of gas filled pipeline, valves, and quick connectors, which should have good pressure-bearing capacity and tightness. According to experimental research, PU tube (polyurethane) meets the requirements of the gas filled pipeline. 


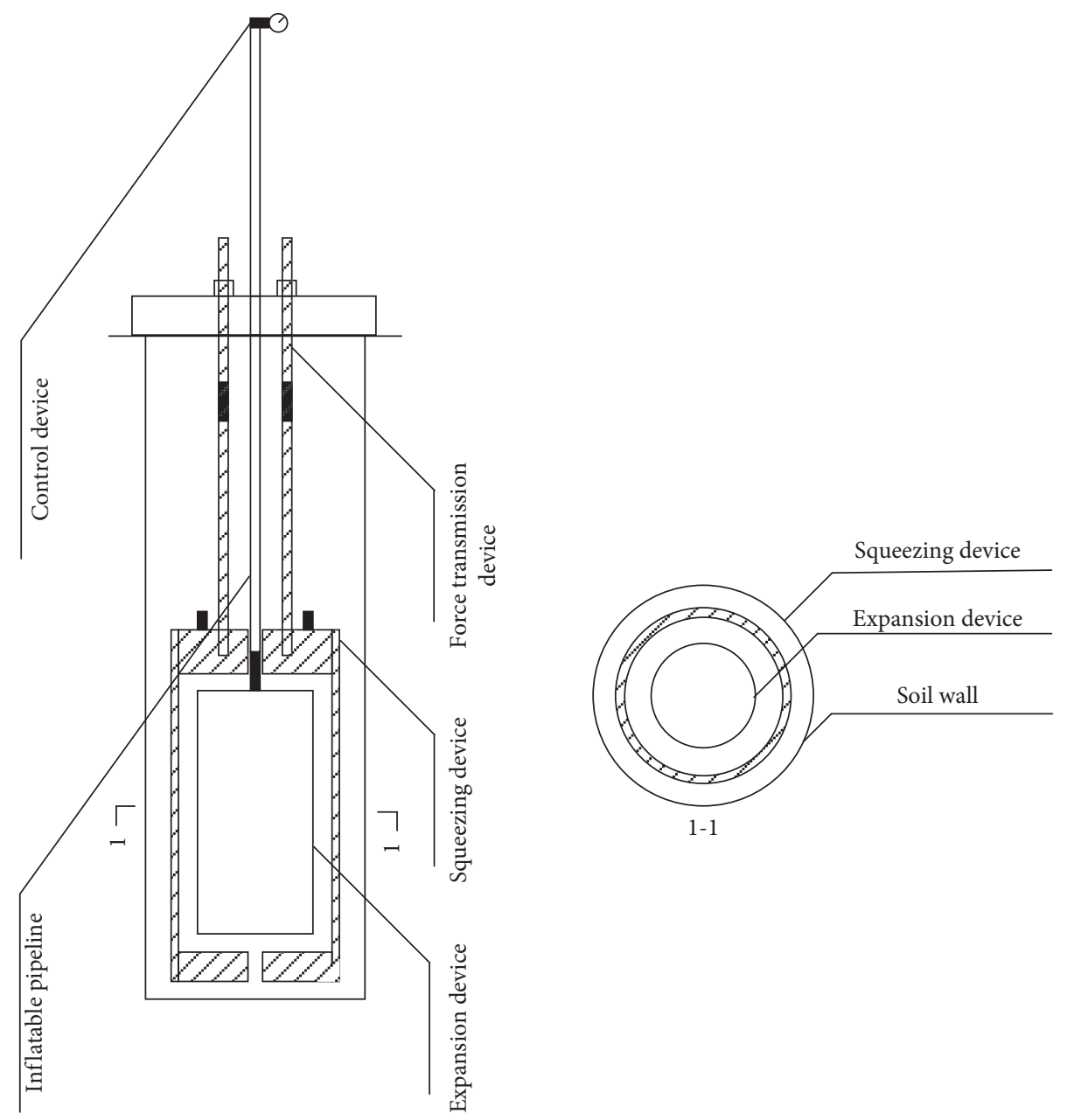

FIgURe 2: Proposed inflatable controlled anchor.

To ensure the air tightness of the connection between the rubber membrane and the gas filled pipe, a quick connector is used to connect the above two parts, which not only enables the anchor section and the control device to be processed independently but also can be quickly disassembled and assembled. The PU tube and the quick connector are shown in Figure 8.

\section{Bearing Capacity Test of Inflatable Controlled Anchor}

3.1. Test Device. The main equipment used in field test include the following: (a) the anchor pull gauge and pressure gauge used to measure pulling force, (b) the dial gauge used to measure the displacement, (c) the counterforce frame used for anchor resistance, (d) the air compressor and its control device used to provide inflation pressure, and (e) the auxiliary equipment such as counterforce transferring plates and sleeve. The structure diagram of the field test model is shown in Figure 9.

The field tests were conducted in the open ground of a proposed project located at Jingzhou City in Hubei Province. The soil hole is formed by the mechanical drilling method in advance, and then the anchor system is placed into the hole. To eliminate the test error, it is necessary to ensure that the hollow jack and the tension bar are on the same axis when the anchor bar are pulled out, which is also the requirement of Chinese regulations for supporting foundation pit of buildings.

The field test system is shown in Figure 10. While carrying out the pull-out test, the counterforce frame should be placed perpendicular to the soil hole. The flatness of the ground can affect the effect of the counterforce frame. The unevenness of counterforce frame will lead to the different axes of the jack, and the anchor after the pull-out load is applied, which influences the accuracy of test results. Therefore, it is necessary to level the field test site before pull-out.

3.2. Physical and Mechanical Properties of Soil. According to the geotechnical survey result, the field site where the foundation pit is located belongs to the first-order terrace geomorphic unit of the Yangtze River. The surface of the site is a miscellaneous fill soil with a thickness of $1.2 \mathrm{~m}$, the second soil layer is silty clay with a thickness of $5.63 \mathrm{~m}$, and the third soil layer is silty sand with a thickness of $6.04 \mathrm{~m}$. According to the geotechnical test method standard [13], the strength parameters of soil layers, such as cohesion and friction angle, are tested by means of laboratory direct shear 


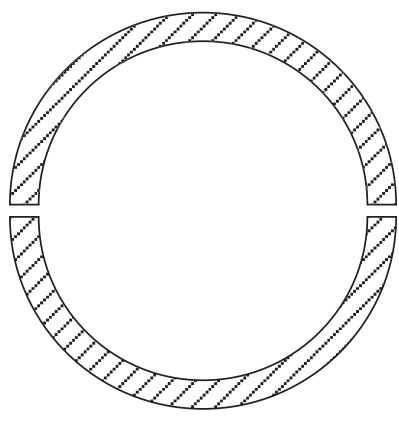

(a)

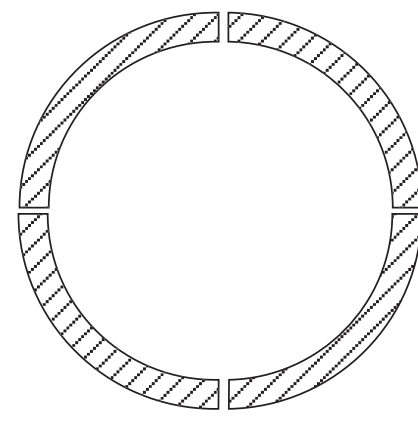

(b)

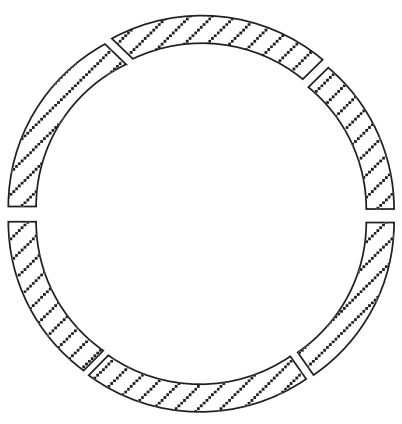

(c)

Figure 3: The section sketch of circular steel tube divided into two, four, and six parts.

TABLE 1: Structural form comparison of steel strips.

\begin{tabular}{|c|c|c|c|}
\hline Structural form & Disadvantage & Advantage & Testing result \\
\hline $\begin{array}{l}\text { The steel tube is divided into two equal } \\
\text { parts longitudinally }\end{array}$ & $\begin{array}{l}\text { Uneven expansion of } \\
\text { squeezing device }\end{array}$ & $\begin{array}{l}\text { The structure is simple, the processing is } \\
\text { convenient, and the expansion is easy } \\
\text { The processing is convenient, the }\end{array}$ & Poor performance \\
\hline $\begin{array}{l}\text { The steel tube is divided into four equal } \\
\text { parts longitudinally }\end{array}$ & $\begin{array}{l}\text { Slightly complicated } \\
\text { structure }\end{array}$ & $\begin{array}{l}\text { expansion of steel strips is easy. The steel } \\
\text { strips have large contact area with the } \\
\text { soil wall }\end{array}$ & $\begin{array}{r}\text { Good } \\
\text { perf }\end{array}$ \\
\hline $\begin{array}{l}\text { The steel tube is divided into six equal } \\
\text { parts longitudinally }\end{array}$ & $\begin{array}{l}\text { Difficult processing and } \\
\text { construction }\end{array}$ & $\begin{array}{c}\text { The expansion of steel strips is easy. The } \\
\text { steel strips have large contact area with } \\
\text { the soil wall }\end{array}$ & Complicated structure \\
\hline
\end{tabular}

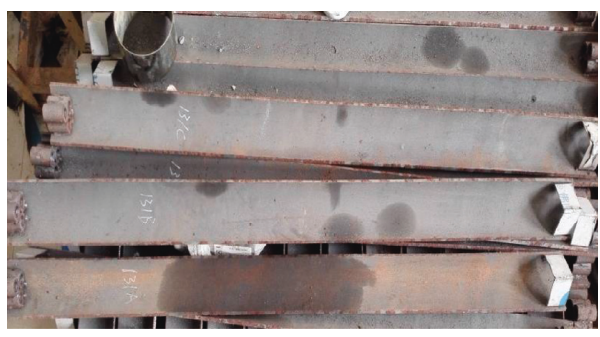

(a)

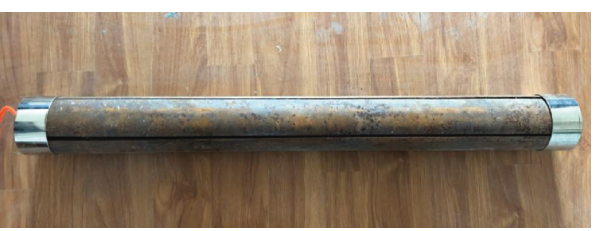

(b)

FIgure 4: Squeezing device. (a) Steel strips. (b) Closure of steel strips.

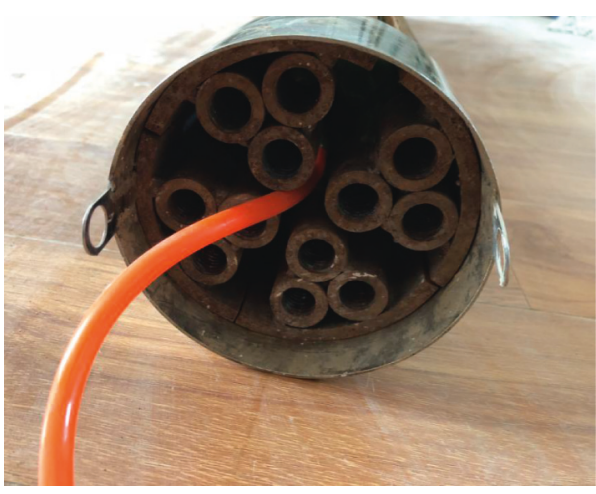

(a)

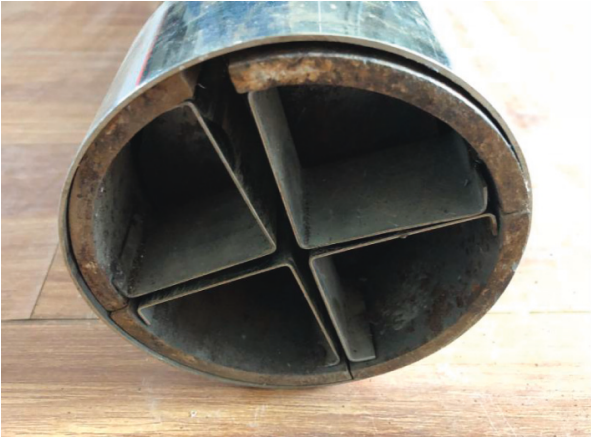

(b)

FIGURE 5: Schematic diagram of two ends of steel strips. (a) Upper end. (b) Lower end.

test, and the compression modulus is tested by laboratory consolidation test under continuous loading with a strain control. The physical and mechanical parameters of soil layers are shown in Table 2.
3.3. Test Sequence. To test the effectiveness of the proposed inflatable controlled anchor, four cases of pull-out tests were performed with different inflation pressures. The depth and diameter of the soil hole are $2 \mathrm{~m}$ and $150 \mathrm{~mm}$, respectively. 


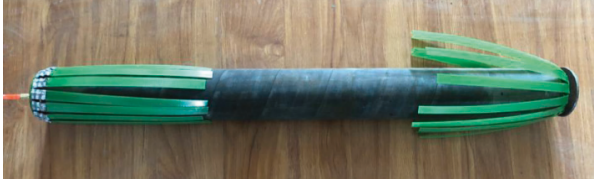

(a)

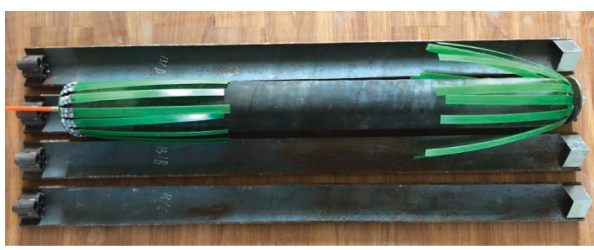

(b)

FIgure 6: Expansion device. (a) Rubber membrane. (b) Rubber membrane and steel strips.

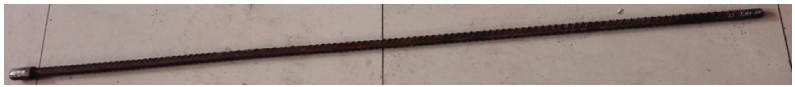

FIgURE 7: The tension bar.

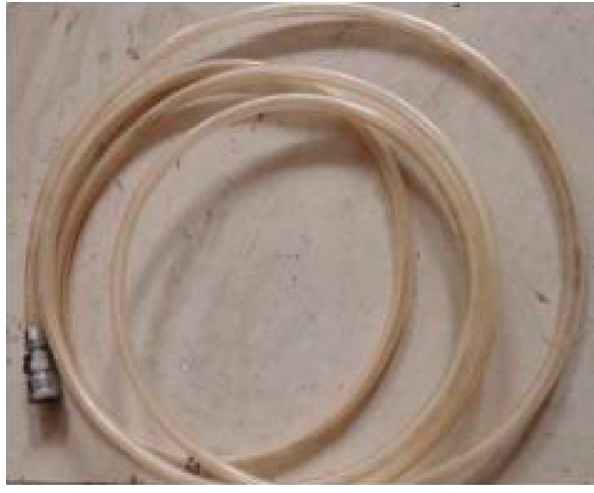

(a)

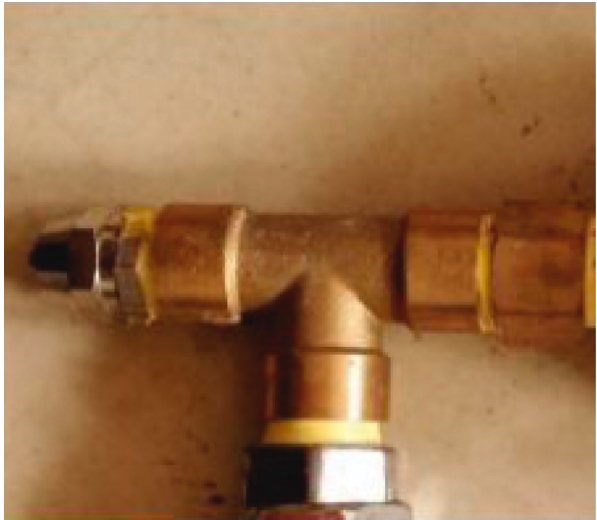

(b)

Figure 8: Control device. (a) PU tube. (b) The quick connector.

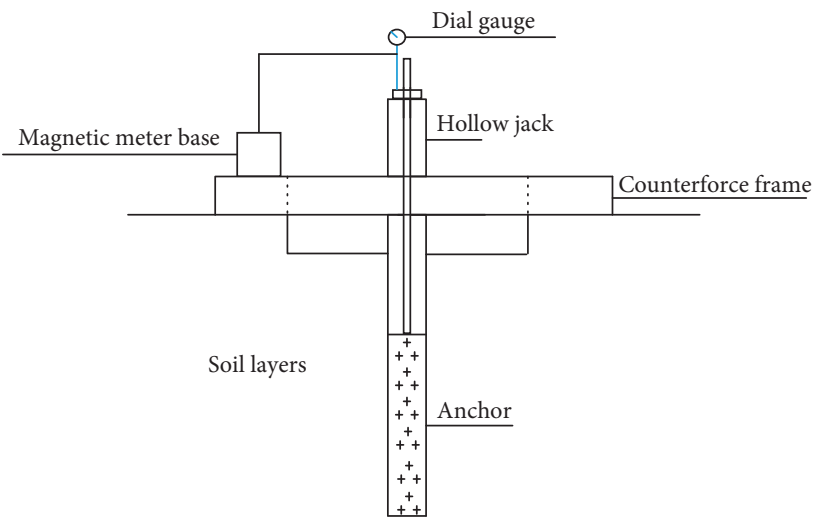

Figure 9: Schematic diagram of field test.

The length, thickness and diameter of the squeezing device are $120 \mathrm{~cm}, 5 \mathrm{~mm}$, and $127 \mathrm{~mm}$, respectively. The length, thickness, and diameter of the rubber membrane corresponding to the expansion device are $100 \mathrm{~cm}, 5 \mathrm{~mm}$, and $100 \mathrm{~mm}$, respectively.

The field test procedure for the inflatable controlled anchor is set as follows: (1) Assemble the inflatable controlled anchor. (2) Position the soil hole and put the anchor in the design depth. (3) Install displacement gauges and

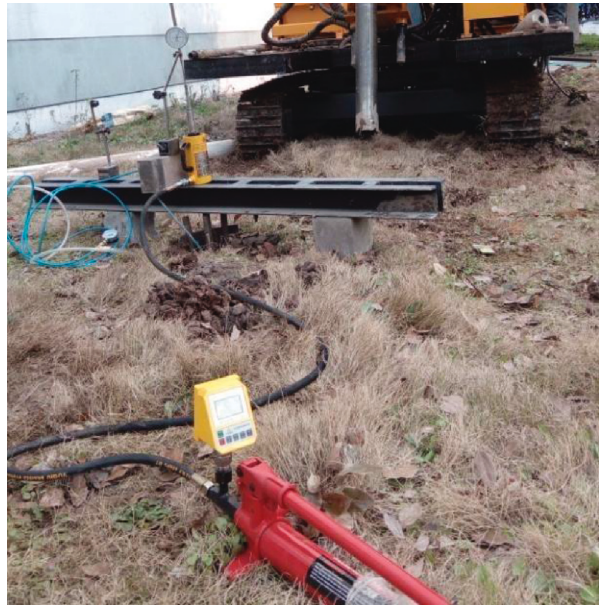

Figure 10: Field test set-up.

jacks. (4) Connect the gas filled pipeline with the rubber membrane. (5) Set and record the initial value of each gauge. (6) Connect the gas source, and pressurize the gas to the designed pressure value. (7) Conduct the pull-out test. (8) Recycle the inflatable controlled anchor.

The assembly sequence of inflatable controlled anchor is carried out as follows: (1) Surround the cylindrical rubber 
TABle 2: Physical and mechanical properties of soil layers.

\begin{tabular}{lccccc}
\hline Soil layer & Thickness $(\mathrm{m})$ & Density $\left(\mathrm{kN} / \mathrm{m}^{3}\right)$ & Cohesion $(\mathrm{kPa})$ & Internal friction angle $\left(^{\circ}\right)$ & Compression modulus $(\mathrm{MPa})$ \\
\hline Miscellaneous fill & 1.20 & 18.0 & 12.0 & 9.0 & - \\
Silty clay & 5.63 & 19.1 & 18.4 & 7.9 & 4.5 \\
Silty sand & 6.04 & 19.3 & 11.1 & 9.7 & 8.5 \\
\hline
\end{tabular}

membrane by four steel strips and fix the closed steel tube by rubber bands. (2) Connect the tension bars to the upper end of squeezing device (as shown in Figure 5(a)).

The field tests are carried out by multistage loading method. The load is applied every 3 minutes and each level of load is about $1 / 15$ of the ultimate load. The data are recorded every minute after loading. When the reading displayed on the gauges is close to the preset value, the loading speed should be slowed down and the load should be stopped when the displacement continues to increase. The schematic diagram of the field test program setting of the inflatable controlled anchor is shown in Figure 11.

\section{Results}

4.1. Test Results of Inflatable Controlled Anchor. The pull-out tests of inflatable controlled anchor are carried out under different inflation pressure. The load-displacement curves are shown in Figure 12. It can be found that the loaddisplacement curve of the developed anchor is basically parabolic under certain inflatable pressure. The curves for 4 cases of inflatable pressure have certain similarity, which shows that the movement of the anchor is of good regularity. When the bearing capacity of inflatable controlled anchor reaches the critical ultimate value, it will drop suddenly and then fluctuate slightly at a certain fixed value and become stable at a residual bearing capacity after a period of time. When the residual bearing capacity is stable, the anchoring force is balanced with the external load, and a large displacement will be produced if a small load is applied because the friction resistance between the anchor and soil is changed from static friction to dynamic friction.

According to ultimate bearing capacity and corresponding displacement of inflatable controlled anchor under different inflation pressure (shown in Table 3), the ultimate bearing capacity of the anchor increases with the increase of the inflation pressure.

From the perspective of the ultimate value of the pull-out capacity, the increment of the ultimate bearing capacity is $83.27 \%, 48.5 \%$, and $39.10 \%$ corresponding to the previous level of inflation pressure, respectively. In addition, with the increase of the inflation pressure, the residual bearing capacity and ultimate displacement also increased obviously. For the ultimate displacement of pull-out tests, the increment of ultimate displacement is $60.51 \%, 9.41 \%$, and $26.77 \%$ corresponding to the previous level of inflation pressure, respectively.

4.2. Comparison with Traditional Grouting Anchor. To verify the structure reasonableness of the inflatable controlled anchor, the test results of inflatable controlled anchor are compared with those of the traditional grouting anchor.

3 groups of traditional grouting anchor have been designed for pull-out tests at the same test site condition. The length of traditional grouting anchor is $2.0 \mathrm{~m}$, in which the anchoring length is $1.2 \mathrm{~m}$ and free length is $0.8 \mathrm{~m}$. The anchor body adopts the hollow steel pipe with diameter of $48 \mathrm{~mm}$ and thickness of $3 \mathrm{~mm}$. The cement mortar with mixture ratio of 1 (cement) to 1 (sand) is selected as the grouting liquid for anchoring. When the cement mortar is cured to a coagulation period of 28 days, the traditional grouting anchors are carried out pull-out tests. The test device is shown in Figure 9.

The measured load-displacement curves of grouting anchors are shown in Figure 13. The ultimate bearing capacity of 3 grouting anchors is $18.5 \mathrm{kN}, 19.5 \mathrm{kN}$, and $21.2 \mathrm{kN}$, respectively. The residual bearing capacity is $11.1 \mathrm{kN}$, $11.6 \mathrm{kN}$, and $12.5 \mathrm{kN}$, and the corresponding ultimate displacement is $19.518 \mathrm{~mm}, 19.539 \mathrm{~mm}$, and $21.932 \mathrm{~mm}$, respectively. The average values of ultimate bearing capacity, residual bearing capacity, and ultimate displacement of grouting anchors are $19.7 \mathrm{kN}, 11.7 \mathrm{kN}$, and $20.330 \mathrm{~mm}$, respectively, where the average residual bearing capacity is $59.39 \%$ of average ultimate bearing capacity.

In general, the curve characteristics of 3 grouting anchors are basically the same during the pullout stage: (1) When the pull-out force is small, the load-displacement curves are approximately linear. (2) After the pull-out force reaches the ultimate value, the load suddenly drops to a certain value and remains basically unchanged, and then the anchor quickly generates a large displacement, which is named as plastic stage.

The average ultimate bearing capacity of traditional grouting anchors is $19.7 \mathrm{kN}$. Compared with the inflatable controlled anchor, the ultimate bearing capacity of grouting anchors is less than that of inflatable controlled anchor if the inflation pressure is increased to $0.2 \mathrm{MPa}$. The ultimate bearing capacity of inflatable controlled anchor is 1.50 times and 2.08 times that of grouting anchor for the inflation pressure $0.3 \mathrm{MPa}$ and $0.4 \mathrm{MPa}$, respectively.

Comparing Figure 12 with Figure 13, the loaddisplacement curves of the inflatable controlled anchor and the grouting anchor are similar before the load reaches ultimate value, but there are obvious differences after the ultimate bearing capacity. When the inflation pressures are $0.1 \mathrm{MPa}, 0.2 \mathrm{MPa}, 0.3 \mathrm{MPa}$, and $0.4 \mathrm{MPa}$, the residual bearing capacity of inflatable controlled anchor are $86.14 \%$, $88 \%, 93.3 \%$, and $87.3 \%$ of its ultimate bearing capacity respectively, while the average residual bearing capacity of grouting anchor is only $59.39 \%$ of the their average ultimate bearing capacity. The high residual bearing capacity is helpful to maintaining the stability of the foundation pit, so 


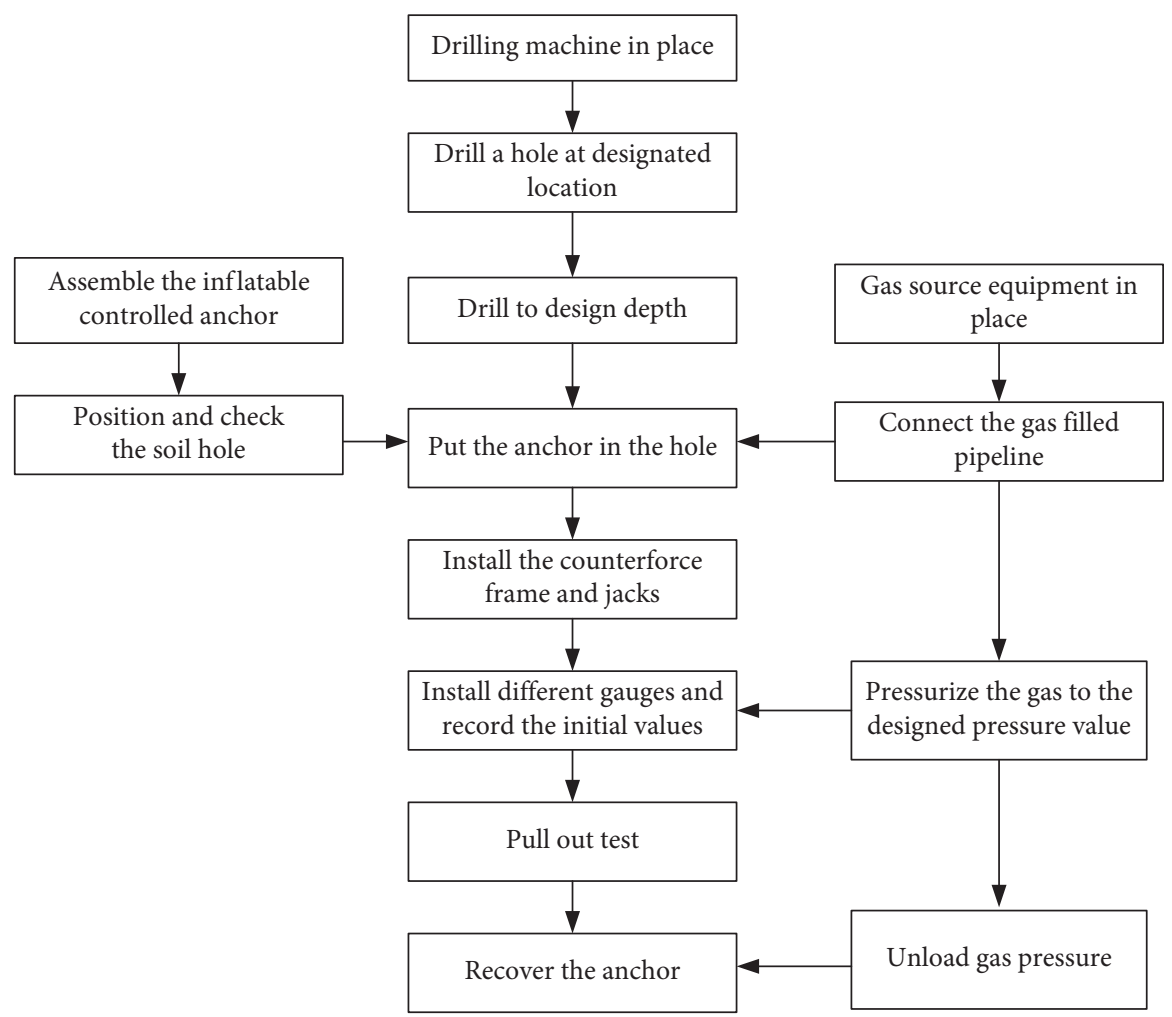

FIgURE 11: Schematic diagram of field test program.

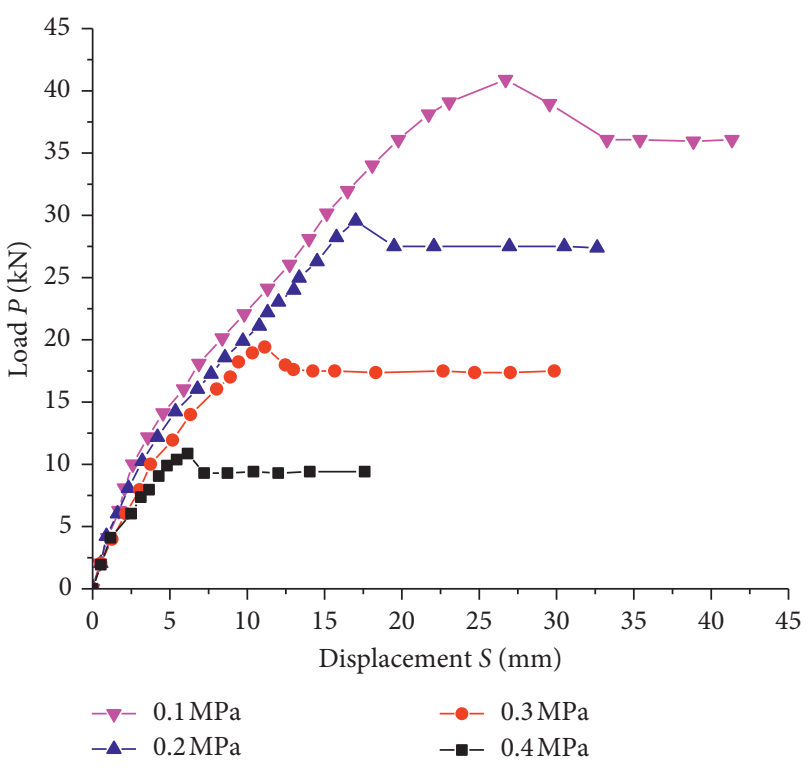

FIGURE 12: The load-displacement curves under different inflation pressure.

it can be seen that the inflatable controlled anchor can play a more significant role in foundation pit support.

\section{Bearing Capacity Model of the Developed Inflatable Controlled Anchor}

5.1. Constitutive Relation of Anchor-Soil Interface. According to the field test layout of inflatable controlled anchor shown in Figure 9, the ultimate bearing capacity of this type anchor is mainly composed of three parts: self-weight, friction resistance, and upper end resistance. The total mass of inflatable controlled anchor is about $18 \mathrm{Kg}$, and the corresponding weight is about $0.18 \mathrm{kN}$. When the inflation pressure is $0.1 \mathrm{MPa}$, the anchor weight accounts for $1.66 \%$ of the ultimate pull-out bearing capacity, and when the inflation pressure is $0.4 \mathrm{MPa}$, the anchor weight accounts for $0.44 \%$ of the ultimate pull-out bearing capacity. Therefore, for simplicity, self-weight of inflatable controlled anchor can be neglected for the prediction of ultimate pull-out bearing capacity.

Before the pull-out test for inflatable controlled anchor, the inflation pressure is gradually increased, the rubber membrane expands and gradually contacts with the steel strips. When the inflation pressure reaches a certain value, the steel strips begin to contact with the soil wall of hole closely, and the diameter of the soil hole gradually enlarges. The essence of inflatable controlled anchor is a type of small enlarged end anchor [14]. Based on the pull-out bearing formula of enlarged pile, the end resistance of inflatable controlled anchor can be defined as

$$
Q_{p}=\beta \mu\left(\gamma_{m} H\right) \frac{\pi\left(D^{2}-D_{0}^{2}\right)}{4},
$$

where $Q_{p}$ is the end resistance, $D_{0}$ is the initial diameter of soil hole, $D$ is the equivalent enlarged diameter of soil hole, $\mu$ is the friction coefficient between steel and soil, and $\beta$ is the correction coefficient of end resistance with the range of from 3.0 to 6.5 [15].

Field tests show that the steel strips contacts closely with the wall of the soil hole when the inflation pressure is 
TABLE 3: Ultimate bearing capacity and corresponding displacement of inflatable controlled anchor.

\begin{tabular}{lcccc}
\hline Test number & Inflation pressure $(\mathrm{MPa})$ & Ultimate bearing capacity $(\mathrm{kN})$ & Residual bearing capacity $(\mathrm{kN})$ & Ultimate displacement $(\mathrm{mm})$ \\
\hline 1 & 0.1 & 10.82 & 9.32 & 18.61 \\
2 & 0.2 & 19.83 & 17.45 & 29.87 \\
3 & 0.3 & 29.46 & 27.50 & 32.68 \\
4 & 0.4 & 40.98 & 36.02 & 41.43 \\
\hline
\end{tabular}

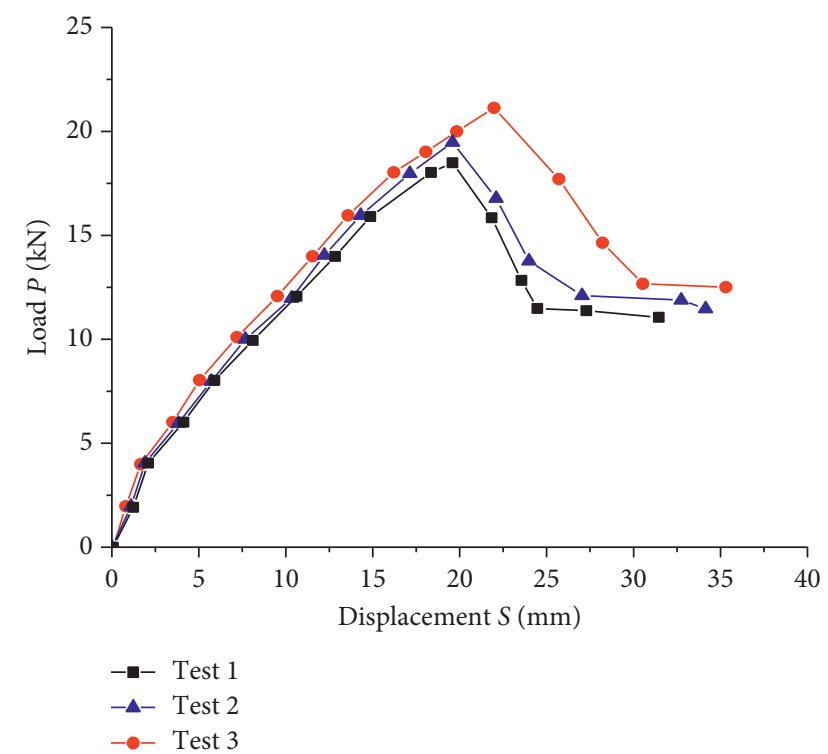

FIGURE 13: The load-displacement curves of traditional grouting anchor.

increased to $0.1 \mathrm{MPa}$, and the small enlarged diameter of the hole can be neglected. When the inflation pressure increases to $0.4 \mathrm{MPa}$, the enlarged diameter of soil hole is about $200 \mathrm{~mm}$, increasing by $50 \mathrm{~mm}$. Assuming $\beta=6.0$ and $\mu=0.16$, the end resistance $Q_{p}$ is $0.197 \mathrm{kN}$ when the inflation pressure is $0.4 \mathrm{MPa}$, which accounts for $0.48 \%$ of the ultimate pull-out bearing capacity. The end resistance is approximately zero when the inflation pressure is $0.1 \mathrm{MPa}$. Due to the large rigidity of the steel sheet, the steel tube composed of steel strips has small radial deformation. The steel strips are in the elastic deformation range, so that the steel tube body meets the recyclable requirements. Compared with the ordinary inflatable anchor, the enlarged diameter of the inflatable controlled anchor is relatively small, and therefore the end resistance can be negligible for the prediction of ultimate pull-out bearing capacity for the developed anchor.

From the load-displacement curves of the inflatable controlled anchor shown in Figure 12, the deformation characteristics of inflatable controlled anchor can be divided into three stages as follows (Figure 14): the elastic stage, the plastic stage, and the failure stage.

(1) Elastic Stage. After the anchor is expanded and the inflation pressure is stabilized, an axial load is applied to the anchor and the relative displacement occurs between the anchoring zone and the wall of soil hole. The displacement generated by axial load is

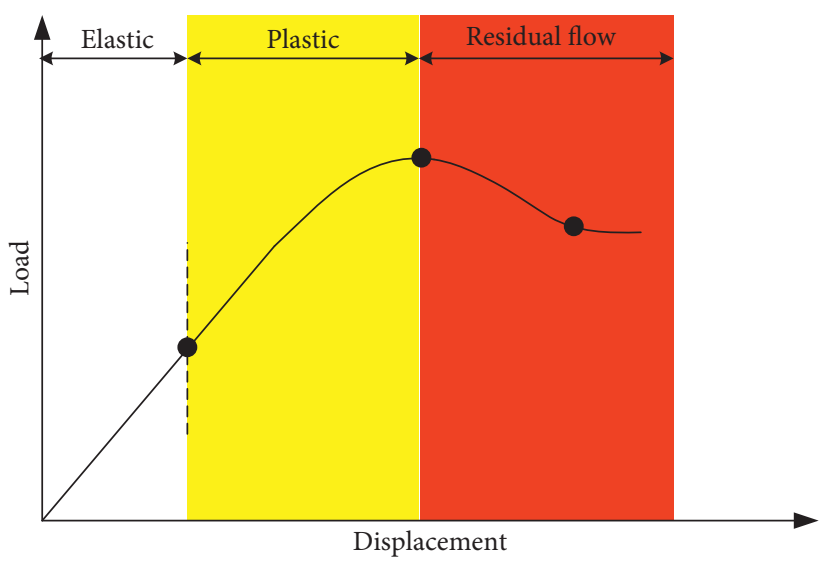

Figure 14: Division of deformation stage for inflatable controlled anchor.

small and the curve is approximately linear in the initial stage. If the axial load is removed, the anchor will resume its original position and the displacement can also be eliminated.

(2) Elastic-Plastic Stage. With the increase of axial load, the relative displacement is increased nonlinearly $[16,17]$. The rubber membrane and the steel strips closely contacted by high inflation pressure and keep consistent in motion. The pulling load is mainly borne by the friction between steel strips and the soil wall. The slope of the curve between displacement and load decreases gradually and when the slope is zero, the axial load reaches the ultimate bearing capacity.

(3) Failure Stage. When the axial load reaches the ultimate bearing capacity, the relative sliding between the anchor and the soil wall occurs, and the anchor deformation increases quickly, the pull-out resistance will gradually decrease and tend to a fixed value, and the anchor is finally pulled out and fails.

5.2. Constitutive Relation of Shear Stress and Displacement. The friction resistance of steel strips plays a decisive role in the ultimate pull-out capacity of the inflatable controlled anchor. The friction resistance is mainly related to the inflation pressure, the stress state of the soil, and the friction coefficient between the steel and the soil. To study the influence of inflation pressure and other factors on the ultimate bearing capacity of inflatable controlled anchor, a whole process constitutive relation of the anchor-soil interface is proposed in this study [18]. 


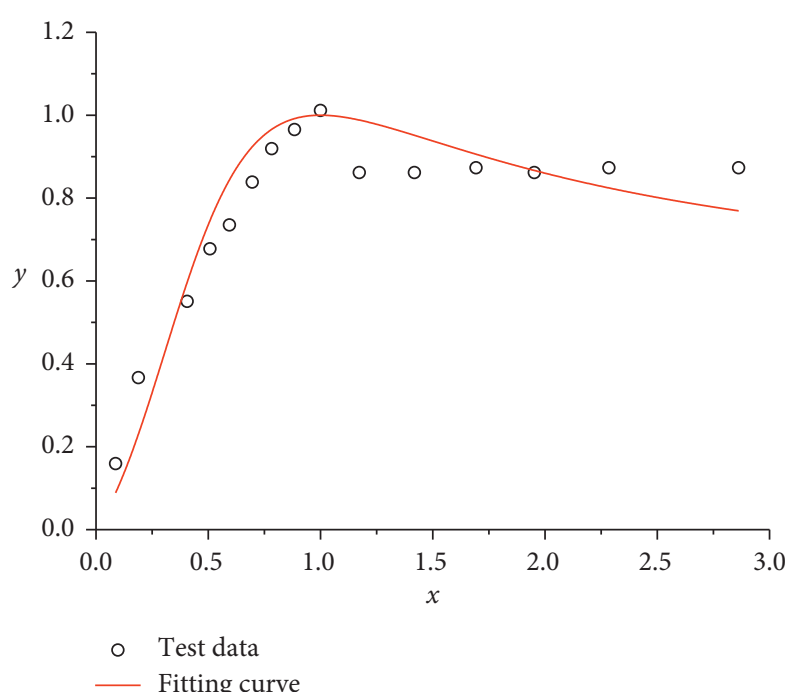

(a)

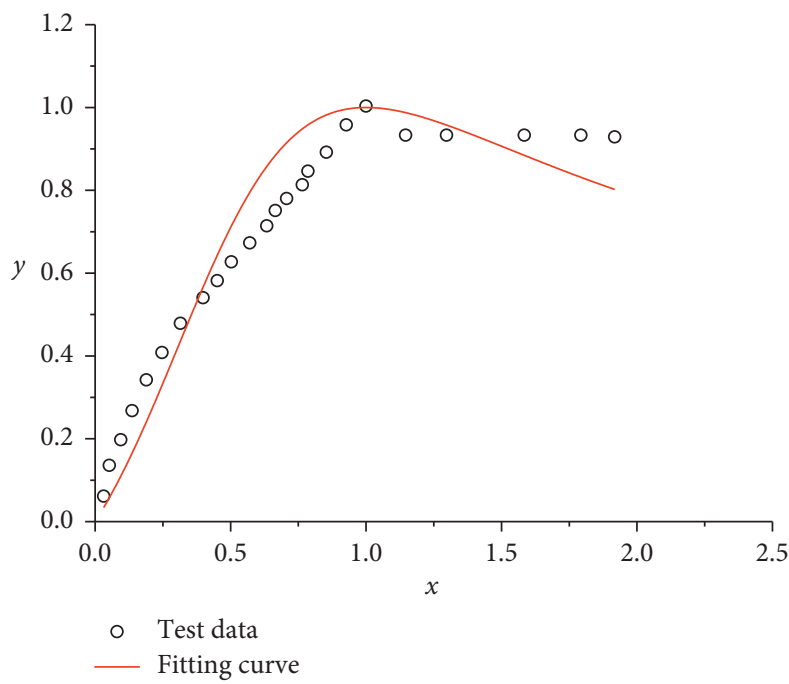

(c)



(b)

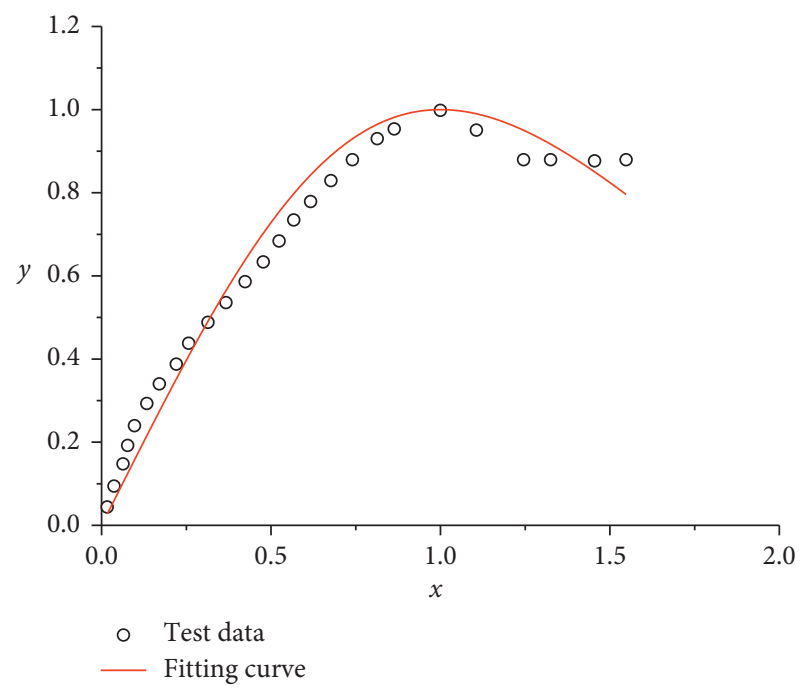

(d)

FiguRE 15: Comparison between calculated curves and measured curves under different inflation pressure. (a) $0.1 \mathrm{MPa}$, (b) $0.2 \mathrm{MPa}$, (c) $0.3 \mathrm{MPa}$, and (d) $0.4 \mathrm{MPa}$.

The load $Q$ and displacement $s$ of the anchor are divided by the peak value $Q_{\mathrm{f}}$ and the peak displacement $s_{\mathrm{f}}$ by the normalization method, respectively. The load ratio $y$ and displacement ratio $x$ can be obtained as follows:

$$
\left\{\begin{array}{l}
y=\frac{Q}{Q_{\mathrm{f}}}, \\
x=\frac{s}{s_{\mathrm{f}}} .
\end{array}\right.
$$

The normalized curves $Q / Q_{\mathrm{f}}-s / s_{\mathrm{f}}$ can be obtained as shown in Figure 15. Through the analysis of curve shape of all tests, the following formula is used to approximate the curves under different inflation pressures:

$$
y=\frac{\alpha x+(\beta-1) x^{2}}{1+(\alpha-2) x+\beta x^{2}},
$$

where $\alpha$ and $\beta$ are model parameters.

The relationship between the ultimate bearing capacity of anchor and the inflation pressure basically meets the linear relationship, which is shown in Figure 16. By substituting equation (2) in equation (3), the constitutive relation of the anchor and soil interface can be obtained as

$$
\begin{aligned}
Q= & \frac{Q_{\mathrm{f}}\left[\alpha s_{\mathrm{f}} s+(\beta-1) s^{2}\right]}{s_{\mathrm{f}}^{2}+(\alpha-2) s_{\mathrm{f}} s+\beta s^{2}}=\left(0.245+100.11 p_{g}\right) \\
& \cdot \frac{\alpha s_{\mathrm{f}} s+(\beta-1) s^{2}}{s_{\mathrm{f}}^{2}+(\alpha-2) s_{\mathrm{f}} s+\beta s^{2}},
\end{aligned}
$$




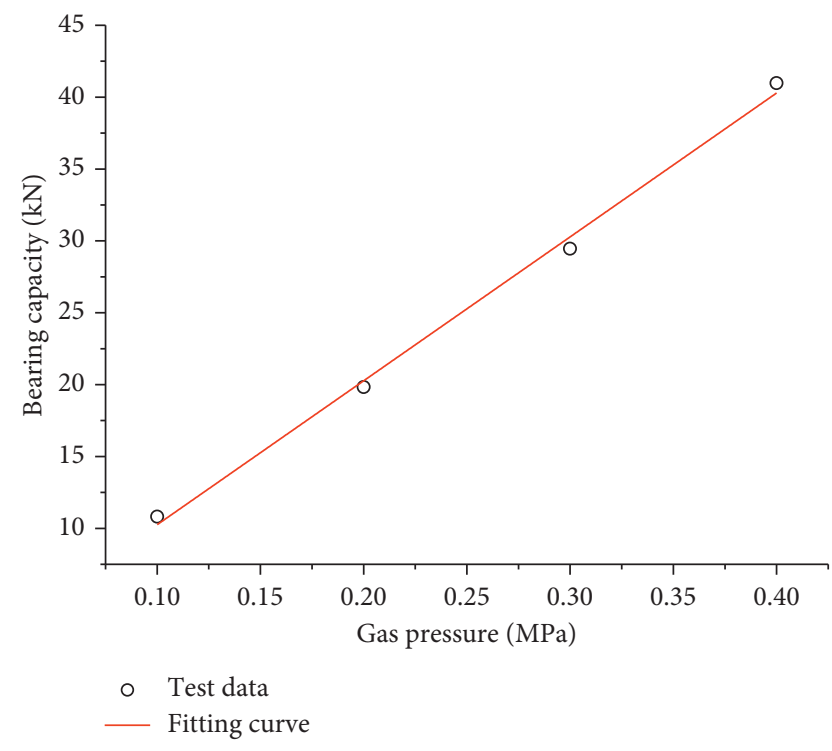

FIGURE 16: Relationship between bearing capacity and inflation pressure.

where $p_{g}$ is the inflation pressure, $\mathrm{MPa}$.

The residual shear strength $Q_{\mathrm{r}}$ of anchor and soil interface can be estimated by the limit of equation (4) as

$$
Q_{\mathrm{r}}=\lim _{s \longrightarrow \infty} Q=\frac{\beta-1}{\beta} Q_{\mathrm{f}} .
$$

After the $Q-s$ expression is obtained, the shear stress of anchor-soil interface $\tau=Q / A$. From this, the constitutive model of the whole process of the anchor-soil interface can be obtained, which is convenient for engineering numerical calculation [19], especially for the numerical simulation of group anchor effect. Generally speaking, the residual shear strength $Q_{\mathrm{r}}$ is not equal to zero, so it still needs to meet the requirement of $\beta \neq 1$.

Through the fitting analysis of the test results (shown in Table 4), it is found that the fitting parameters of $\alpha$ and $\beta$ are different with changed inflation pressure. The general trend is that with the increase of the inflation pressure, $\alpha$ has a trend of gradual increase, while $\beta$ has a trend of gradual decrease. Further experiments are needed to demonstrate the relationship between model parameters and inflation pressure.

\section{Conclusions}

Based on the field tests of an inflatable controlled anchor system, the following conclusions can be drawn:

(1) A new type of inflatable anchor system is designed and developed, which mainly includes four separate parts: squeezing device, expansion device, force transmission device, and control device. The expansion device is enclosed with the squeezing device, which can be dynamically controlled and set. The radial enlargement of expansion device pushes the squeezing device to contact with the hole wall tightly, and the friction resistance generated by the
TABLE 4: Fitting results under different inflation pressure.

\begin{tabular}{lcc}
\hline Inflation pressure $(\mathrm{MPa})$ & $\alpha$ & $\beta$ \\
\hline 0.1 & 0.8315 & 2.1209 \\
0.2 & 0.7998 & 2.2306 \\
0.3 & 1.0293 & 1.3912 \\
0.4 & 1.6201 & 0.4418 \\
\hline
\end{tabular}

expansion device is transmitted directly to the anchor plate outside the hole, thus forming the anchorage system. The material selection, performance requirements, processing, and assembly for anchor system were determined, and then a complete set of inflatable controlled anchor was manufactured for field tests.

(2) The field test results show that the ultimate bearing capacity of the inflatable controlled anchor increases with inflation pressure and is greater than that of the traditional grouting anchor when the inflation pressure is greater than $0.2 \mathrm{MPa}$. When the inflation pressure is $0.3 \mathrm{MPa}$ and $0.4 \mathrm{MPa}$, the ultimate bearing capacity of inflatable controlled anchor are 1.50 and 2.08 times that of grouting anchor, respectively.

(3) The bearing capacity of inflatable controlled anchor is composed of end resistance and friction resistance, and the friction resistance plays a decisive role. A full-process constitutive model for the interface between anchor and soil is proposed. The calculation results show that the calculated curve of the proposed model is in good agreement with the experimental curve and can reflect the actual deformation of the anchor-soil interface.

(4) After the anchorage target is achieved, the expansion device can shrink by unloading the gas pressure and then the squeezing device is separated from the wall of the anchor hole, so the steel strips and rubber membrane in the anchor hole can be recovered completely. A series of field tests prove that the inflatable controlled anchor has good engineering application potential. It not only has the advantages of simple construction and low price, but also has the advantages of recovery, quick formation of anchoring force, and adjustable anchoring force.

\section{Data Availability}

The data used to support the findings of this study are included within the article.

\section{Conflicts of Interest}

There are no conflicts of interest.

\section{Acknowledgments}

The authors gratefully acknowledge the support of the Natural Science Foundation of China (grant no. 51678066). 


\section{References}

[1] C. Liang-kui, H. Jian-lin, and Z. Pei-wen, "The new development of ground anchorage in China," Industrial Construction, vol. 40, no. 1, pp. 98-101, 2010, in Chinese.

[2] R. S. Merifield and S. W. Sloan, "The ultimate pullout capacity of anchors in frictional soils," Canadian Geotechnical Journal, vol. 43, no. 8, pp. 852-868, 2006.

[3] M. M. El Sharnouby and M. H. El Naggar, "Numerical investigation of the response of expansion anchors used to attach helical pile connectors to concrete foundations," $\mathrm{Ca}$ nadian Journal of Civil Engineering, vol. 37, no. 6, pp. 866-877, 2010.

[4] T. Chun-an, Z. Xing-dong, W. Wei-gang, and T. Jun, "Testing study on a new kind of fully-anchored and multi-wedged slotted tube bolt (bamboo-like bolt) researched in laboratory," Chinese Journal of Rock Mechanics and Engineering, vol. 23, no. 3, pp. 465-468, 2004, in Chinese.

[5] Y. Hai-qing, Z. Xiao-ping, and Z. Yong-xing, "Analytical model for split-set rock bolt under pull-out force," Rock and Soil Mechanics, vol. 28, no. 1, pp. 236-240, 2007, in Chinese.

[6] Z. Cheng-xin, L. Hai-yan, and Z. Jin-bo, "Test and application of hydraulic swelling bolt," Coal Science and Technology, vol. 30, no. 2, pp. 18-20, 2002, in Chinese.

[7] Q. Chang, H. Zhou, Z. Xie, and S. Shen, "Anchoring mechanism and application of hydraulic expansion bolts used in soft rock roadway floor heave control," International Journal of Mining Science and Technology, vol. 23, no. 3, pp. 323-328, 2013.

[8] T. S. Gallacher, Novel Anchoring Systems for Remotely Operated Vehicles, University of Dundee, Dundee, UK, 2000.

[9] T. A. Newson, F. W. Smith, P. Brunning et al., "An experimental study of inflatable offshoreanchors," in Proceedings of the ISOPE2003 Conference, pp. 345-356, Honolulu, HI, USA, May 2003.

[10] T. Newson, S. Hinchberger, and Y. Liang, "The mechanics of inflatable Anchors in cohesionless soil," Soils and Foundations, vol. 49, no. 3, pp. 409-420, 2009.

[11] C. Jia-wen, P. Zhen-bin, and P. Wen-xiang, "Experimental study on mechanical characteristics of inflatable anchors in soft clay," Chinese Journal of Geotechnical Engineering, vol. 33, no. 9, pp. 1399-1404, 2011, in Chinese.

[12] C. Qiu-nan, J. Liu-ni, H. Xiao-cheng, L. Wen-jun, and M. Xiang-qian, "Experimental study on the group anchor effect of inflatable anchors in clay," Chinese Journal of Applied mechanics, vol. 35, no. 5, pp. 944-949, 2018, in Chinese.

[13] National Standard of the People's Republic of China, Geotechnical Test Method Standard (GB/T50123-199), China Planning Press, Beijing, China, 1999.

[14] Z. Qing-yi, Y. Xiao-yang, and Y. Chang-ya, "Mechanical mechanism and calculation method of bit expanded anchor rods," Rock and Soil Mechanics, vol. 31, no. 5, pp. 1359-1366, 2010, in Chinese.

[15] D. Jian-hua, Y. Fang-long, and D. Xu-guang, "Mechanical behaviors and analysis of a new supporting structure of deep foundation pit," China Civil Engineering Journal, vol. 50, no. 10, pp. 99-110, 2017, in Chinese.

[16] Y. Liang, S. D. Hinchberger, and T. A. Newson, "Non-linear analysis of pullout tests on inflatable anchors in sand," in Proceedings of the Canadian Geotechnical Conference, pp. 1-8, Halifax, Canada, September 2009.

[17] H. Niroumand and K. A. Kassim, "Pullout capacity of irregular shape anchor in sand," Measurement, vol. 46, no. 10, pp. 3876-3882, 2013.
[18] S. Yang, Z. Wu, X. Hu, and J. Zheng, "Theoretical analysis on pullout of anchor from anchor-mortar-concrete anchorage system," Engineering Fracture Mechanics, vol. 75, no. 5, pp. 961-985, 2008.

[19] W. Nie, Z. Y. Zhao, Y. J. Ning, and W. Guo, "Numerical studies on rockbolts mechanism using 2D discontinuous deformation analysis," Tunnelling and Underground Space Technology, vol. 41, pp. 223-233, 2014. 


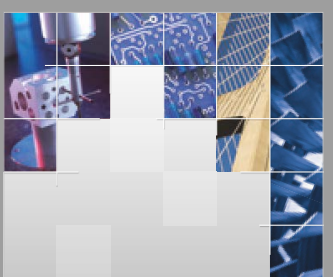

\section{Enfincering}
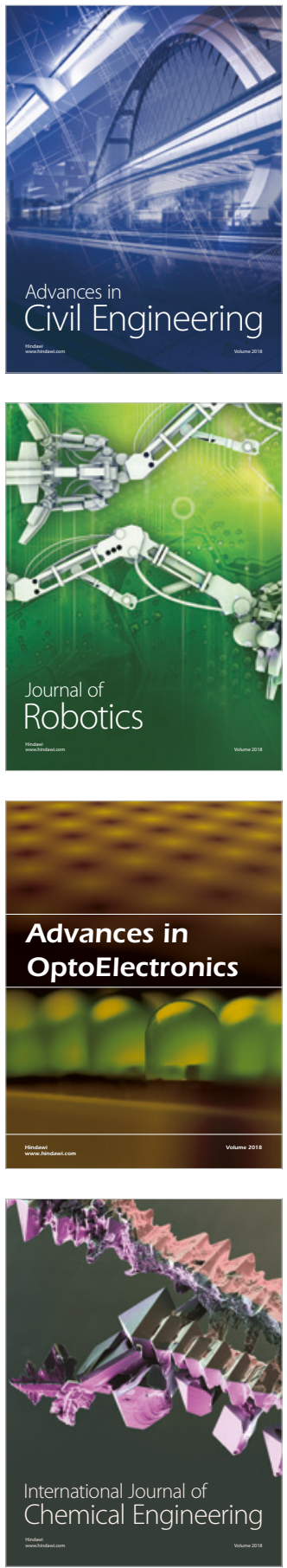

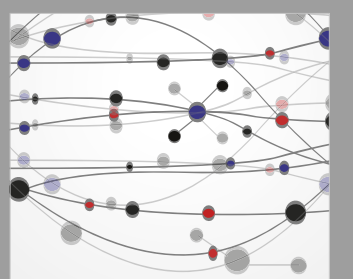

\section{Rotating \\ Machinery}

The Scientific World Journal

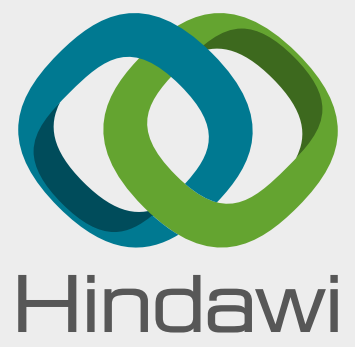

Submit your manuscripts at

www.hindawi.com
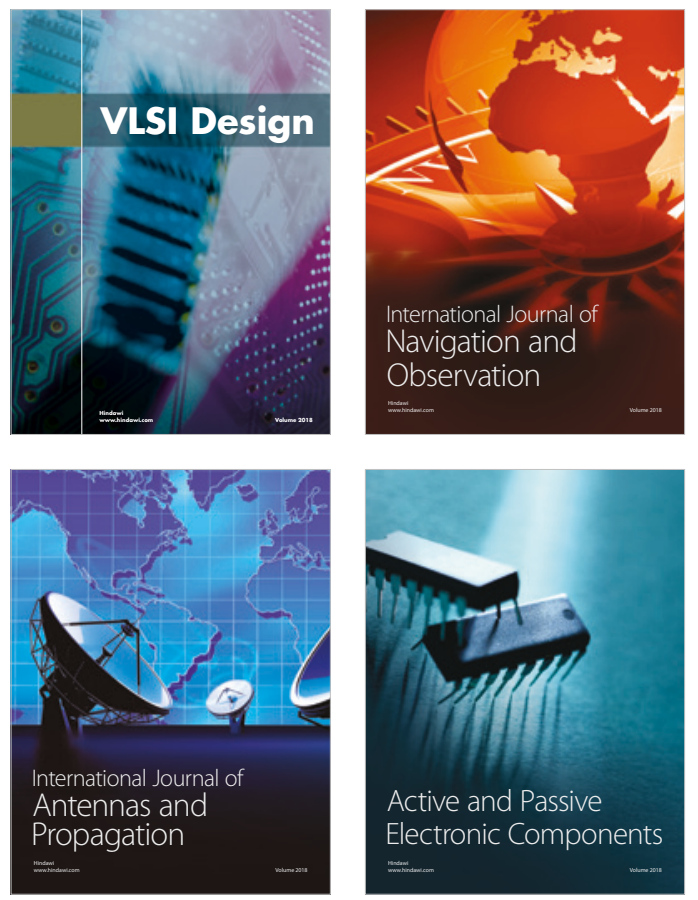
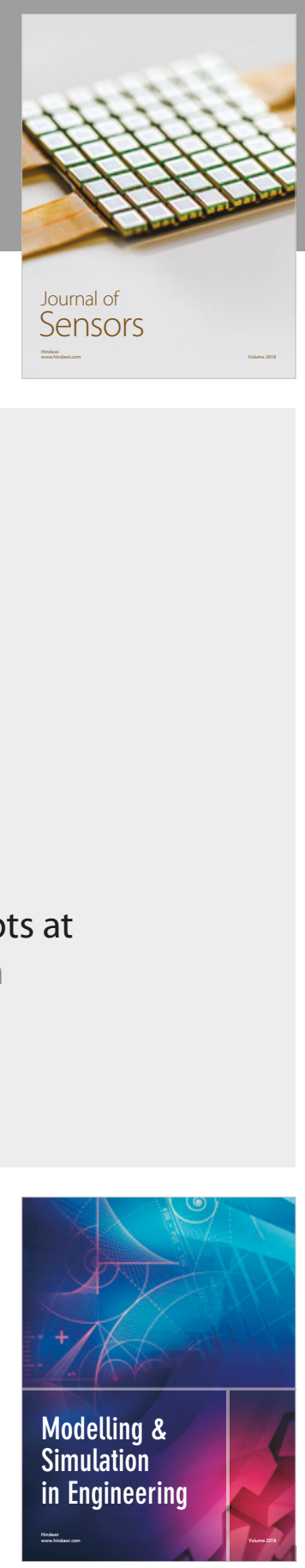

\section{Advances \\ Multimedia}
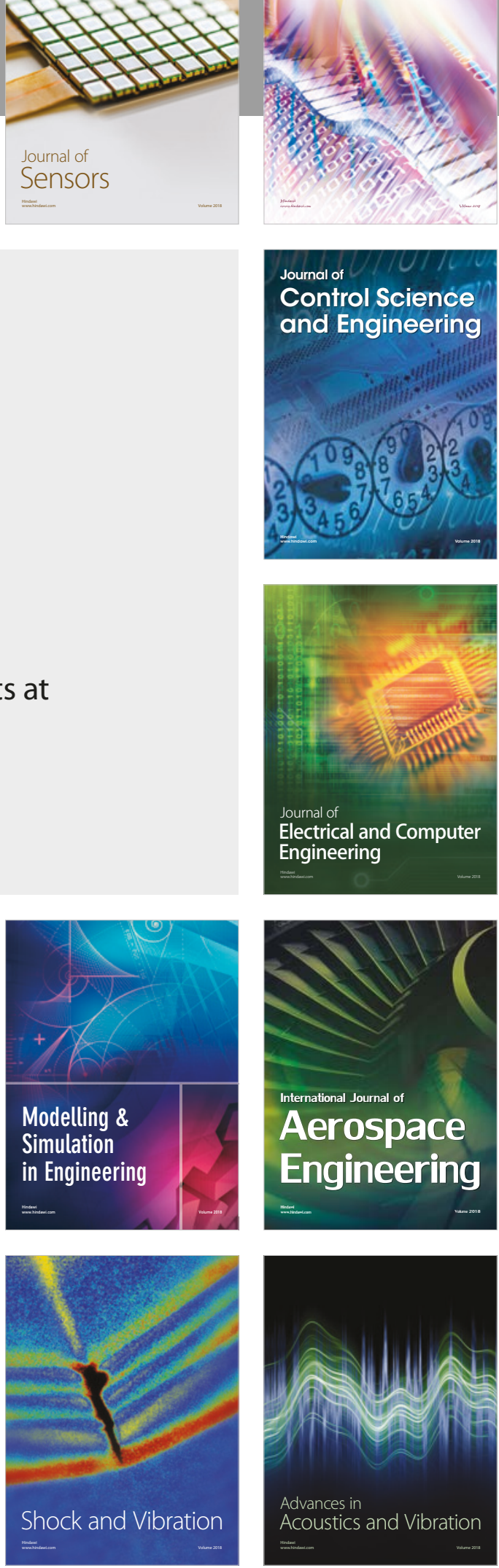